\title{
A study on the development of an infographic reader questionnaire and reader opinions
}

\author{
Serkan Yıldırım ${ }^{1, *}$, Embiya Çelik ${ }^{2}$, Gürkan Yıldırım ${ }^{3}$, and Abdullatif Kaban ${ }^{3}$ \\ ${ }^{1}$ Atatürk University, Kazım Karabekir Educational Faculty, Erzurum, Turkey \\ ${ }^{2}$ Atatürk University, Open Education Faculty, Erzurum, Turkey \\ ${ }^{3}$ Bayburt University, Educational Faculty, Bayburt, Turkey
}

\begin{abstract}
Educational materials are commonly used to assist with communication during learning. One of the ways to determine the use of educational materials and their contribution to the learning process is to ask students for their opinions. Student opinions provide useful information regarding various objectives such as making both the learning process and resources more effective, bringing about the necessary improvements and organising the teaching process. In this study, we developed a questionnaire for determining the opinions of information graphics (infographics) readers on information graphics prepared for teaching purposes. This study was conducted in the fall semester of the 2013-2014 academic year with the participation of 59 students from the Department of Computer and Instructional Technologies Education of the Kazım Karabekir Faculty of Education. The students were provided with a questionnaire consisting of 29 items that inquired their opinions on infographics. The collected data were assessed using Principal Component Analysis. Based on the analysis results, a second questionnaire consisting of 23 items and six factors (Learnability, Selection Preferences, Sharing, Basic Presentation Structure, Memorability, and Role in the Learning Process) was developed. According to the study results, the students considered infographics as highly instructive, and described that they help ensure a more lasting learning experience.
\end{abstract}

\section{Introduction}

Web 2.0 technologies and changes in content development approaches have enabled web content to be both developed and distributed by media users (1). Thus, users of web-based media have also gained a creator identity in relation to the information on such media (2). At the same time, web technologies and new educational environments have started to contribute to the teaching processes. Thus, the learning process has gone beyond the classroom walls, and the learning process can now be carried out in different environments. This change has manifested itself in the materials used for educational purposes. Materials

\footnotetext{
* Corresponding author: serkanyildirim@atauni.edu.tr
} 
or environments that enable the presentation and assessment of various forms of information have become increasingly commonplace.

Visuals - one of the forms used for presenting information - allow for displaying a certain situation and presenting information in an organised manner through the use of visual components (3). The visualisation of information, the use of visuals in educational environments, and the selection of visuals among many different visuals presenting the same information are quite important. Various factors play a role in this selection, including the characteristics and purpose of use of the information to be conveyed, and characteristics of learners (4)

Graphics are among the visuals used to convey information. Graphics enable information to be more visual, such that comparisons can be made more easily. Thus, a piece of information that may normally require several pages of text can be conveyed to the reader through a single graphic. Graphics are generally used to visualise a certain piece of information. Today's learning approach enables the one-dimensional information provided by classical graphics to be presented by being combined with certain techniques and other educational methods. Known as infographics (information graphics), these new materials allow for information to be conveyed in a certain flow and in the desired context (5). Thus, abundant information can be presented by using visual supports and very few explanatory statements.

Infographics can be defined as the visual representation of information in a certain flow through various illustration and texts. Infographics are composed of many components, such as pictures, graphs, tables, flow diagrams, texts, etc. (5). Infographics enable the presentation of information in a logical order and a relational structure. Used to visualise information and enabling information to be presented in various visual forms, infographics have taken their place among the new trends of present-day learning approaches (6). Wellprepared infographics allow the presentation of important information in an organised manner. Among the strengths of infographics are their flexibility, their ability to visualise information and to be prepared in various forms (7).

One of the innovations introduced by infographics is the use of various visual and diagrammatic components in presenting information and the understanding of constructing the content (8). In preparing an infographic, one should organise the information very diligently, convey recallable and comparable information (9), and organise the flow of information in the graphics very well. These are the necesary steps for preparing infographics that present information in an understandable format. Furthermore, infographics can be used for different purposes such as reminding certain information, demonstrating the relationship between concepts, presenting a course content, and summarising what has been taught (10).

Depending on the multimedia components they have, infographics can be classified as interactive, semi-interactive and non-interactive (9). Non-interactive infographics have static text and visual components (9). In such infographics, the information conveyed is limited to the content presented. In addition to the features of non-interactive infographics, interactive infographics allow for the use of various sources of information in the same or different environments (9). For instance, interactive infographics may contain a video, audio or animation relating to the content. Moreover, infographics that allow the user to search, select or access different information based on the selection made are also included in this category. They thus enable the information to be presented as a whole and make it possible to use components that satisfy the need for information.

Infographics prepared for educational purposes allow information to be presented within a given context. Davis and Quinn (11) noted that high-quality infographics are useful for promoting student development. Furthermore, infographics are regarded as an effective communication tools (12). Visuals have a high level informativeness when they are 
prepared according to the schema of the learners (4). Similarly, learning through the use of infographics may ensure reception of information in an organised manner $\backslash$ and constitute a basis for the schemas which individuals need to form in their minds.

Today, infographics have become popular media commonly used to present various information. There are only a few studies that demonstrate user understanding in relation to infographics that have been rendered attractive through the use of visual design principles and have large audience on the web. It is quite important to determine the usage of infographics and demonstrate reader preferences, such that these tools can be used in teaching environments, and an understanding regarding their design can be developed. In this context, this study aims to devise a questionnaire form that will demonstrate the opinions of learners that read infographics for educational purposes.

\section{Methods}

\subsection{Study Purpose}

The current study aims to devise a questionnaire that will demonstrate the opinions of infographic readers in relation to the use of infographics during learning processes, and to convey the opinions of infographic readers.

\subsection{Study Sample}

The study sample consisted of 59 students (26 male and 33 female) from the Kazım Karabekir Faculty of Education, Department of Computer and Instructional Technologies Education at Atatürk University. The study was conducted in the Fall semester of the 20132014 academic year. The sampling method employed in the study was purposive sampling, which is a type of nonprobability sampling. Purposive sampling allows researchers to easily reach the group, with the group being ready for the application of study procedures (13). This method is frequently used in studies where respondents take part voluntarily (14).

\subsection{Scale Development Process}

The scale development process consisted of three stages. In the first stage, the relevant literature was reviewed, the factors that would demonstrate the reader opinions in relation to the use of infographics for educational purposes were identified based on the views of experts, and 32 preliminary items were written down. A 5-point Likert scale was used to assess the items. The format of the 5-point Likert scale was as follows: 1: (Strongly disagree); 2: (Disagree); 3: (Neither agree nor disagree); 4: (Agree); 5: (Strongly agree).

In the second stage, the items were presented to the evaluation of two linguists, and a pilot study was conducted. Fifty six students registered in the Department of Computer and Instructional Technologies Education took part in the pilot study. The statements in the scale were corrected based on the feedbacks obtained in the second stage. In the last stage of the scale development process, construct validity was tested. 59 students were asked to fill in the scale form to test the construct validity. The scale was analysed using the Principal Components Analysis, after which the scale was given its final form. Internal consistency of the scale was tested using Cronbach's Alpha reliability test.

\subsection{Collection and Analysis of Data}

The data were collected using the printed questionnaire form. All study participants were verbally informed about the study. The SPSS 18 statistical package software was used for 
the statistical analysis of the data. The factor analysis was performed using Principal Component Analysis and Varimax rotation. In this technique, a set of numerous variables considered to be correlated is converted to a set with a smaller number of uncorrelated (or minimally correlated) components.

\section{Results}

\subsection{Factor (Principal Component) Analysis}

Following the factor analysis, a scale consisting of 6 factors and 23 items was developed. Nine preliminary items were removed from the scale due to low loading values. Table 1 shows the results of the converted principal component analysis.

Table 1. Results of the Factor Analysis (Rotated Principal Component Analysis)

\begin{tabular}{|c|c|c|c|c|c|c|c|c|}
\hline \multirow{2}{*}{$\begin{array}{l}\text { Item } \\
\text { No. } \\
\end{array}$} & \multirow{2}{*}{$\begin{array}{l}\text { Factor } \\
\text { Covariance }\end{array}$} & \multirow{2}{*}{$\begin{array}{l}\text { Factor } 1 \\
\text { Loading }\end{array}$} & \multicolumn{6}{|c|}{ Loading After Rotation } \\
\hline & & & Factor 1 & Factor 2 & Factor 3 & Factor 4 & Factor 5 & Factor 6 \\
\hline 4 & 0.852 & 0.635 & 0.886 & 0.150 & -0.076 & 0.058 & -0.168 & 0.085 \\
\hline 5 & 0.756 & 0.616 & 0.851 & 0.005 & 0.042 & -0.022 & -0.039 & 0.170 \\
\hline 7 & 0.685 & 0.724 & 0.740 & 0.296 & 0.158 & 0.136 & 0.078 & 0.013 \\
\hline 6 & 0.598 & 0.665 & 0.726 & 0.141 & 0.147 & 0.066 & 0.056 & 0.147 \\
\hline 8 & 0.628 & 0.663 & 0.548 & 0.419 & 0.094 & 0.037 & 0.219 & 0.000 \\
\hline 12 & 0.651 & 0.371 & 0.122 & 0.792 & -0.087 & -0.012 & -0.011 & 0.006 \\
\hline 10 & 0.770 & 0.663 & 0.377 & 0.779 & -0.005 & 0.100 & -0.014 & 0.105 \\
\hline 11 & 0.598 & 0.448 & 0.287 & 0.638 & 0.256 & 0.058 & -0.123 & 0.156 \\
\hline 9 & 0.657 & 0.361 & -0.201 & 0.620 & 0.130 & 0.026 & 0.207 & 0.414 \\
\hline 15 & 0.736 & 0.314 & 0.058 & 0.039 & 0.831 & 0.118 & -0.134 & 0.097 \\
\hline 13 & 0.628 & 0.358 & 0.127 & 0.040 & 0.751 & 0.194 & -0.088 & 0.035 \\
\hline 16 & 0.684 & 0.349 & 0.095 & -0.041 & 0.743 & -0.091 & 0.218 & 0.256 \\
\hline 14 & 0.606 & 0.077 & -0.078 & 0.179 & 0.617 & -0.142 & 0.262 & 0.315 \\
\hline 18 & 0.812 & 0.432 & -0.043 & 0.030 & 0.027 & 0.862 & 0.174 & 0.188 \\
\hline 17 & 0.755 & 0.447 & 0.131 & -0.001 & 0.018 & 0.851 & -0.039 & 0.108 \\
\hline 19 & 0.408 & 0.500 & 0.081 & 0.198 & 0.102 & 0.554 & 0.222 & 0.313 \\
\hline 23 & 0.680 & 0.058 & -0.205 & 0.042 & 0.020 & -0.166 & 0.770 & 0.122 \\
\hline 22 & 0.631 & 0.255 & 0.027 & -0.100 & -0.016 & 0.242 & 0.749 & 0.006 \\
\hline 21 & 0.701 & 0.674 & 0.486 & 0.191 & -0.041 & 0.320 & 0.565 & 0.069 \\
\hline 20 & 0.635 & 0.623 & 0.268 & 0.107 & 0.205 & 0.431 & 0.553 & 0.132 \\
\hline 1 & 0.794 & 0.525 & 0.108 & 0.203 & 0.017 & 0.184 & -0.022 & 0.840 \\
\hline 2 & 0.703 & 0.540 & 0.178 & -0.118 & 0.205 & 0.415 & 0.081 & 0.660 \\
\hline 3 & 0.656 & 0.597 & 0.425 & -0.061 & 0.020 & 0.122 & 0.272 & 0.618 \\
\hline
\end{tabular}


According to the results of the factor analysis, the readers' opinions on infographics consisted of 6 factors. The first factor consists of 3 items and explains the level of informativeness of infographics. It explained $16.516 \%$ of the total variance. Factor 1 was named as "Informativeness". The second factor shows the preferences of readers in selecting the infographics they will use in the learning processes. This factor consisted of 5 items and explained $11.398 \%$ of the total variance. It was named as "Selection Preferences". The third factor was named as "Sharing". This factor contained 4 items related to the readers' tendency to share infographics with other readers, and explained $10.597 \%$ of the total variance. The fourth factor demonstrated the characteristics of the information presented by infographics, and the approaches of the readers according to the sources. This fourth factor was named as "Basic Presentation Structure". It consisted of 4 items and explained $10.394 \%$ of the total variance. The fifth factor consisted of 3 items. It explained $9.696 \%$ of the total variance, and was named as "Memorability". The last factor demonstrated how readers consider infographics in their learning process. This factor consisting of 4 items was named as "Role in Learning Process," and explained 9.329\% of the total variance. Items constituting the scale and their loading values are shown in Table2.

Table 2. Scale Factors, Items, and Loadings of Items

\section{Informativeness}

1. Visual representations used in infographics facilitate learning.

2. I think infographics are more informative compared to long texts.

0.660

3. In infographics, presentation of information within a context facilitates learning.

0.618

2. Selection Preferences

4. I look at the title of the subject when choosing an infographic to read.

5. I look at the visuals used in the content when choosing an infographic to read.

0.851

6. I look at the content when choosing an infographic to read.

0.726

7. I look at the person or organization that prepared it when choosing an infographic to read.

0.740

8. I prefer that it has social media sharing tools when choosing an infographic to read.

0.548

3. Sharing

9. Among the different sources of learning with visual representations, I especially recommend infographics to people around me.

10.I share the infographics, which I liked, to my friends who may be interested.

11.I share infographics that are prepared in compliance with copyrights.

0.779

0.638

12.I share the infographics that I like on social media platforms.

0.792

4. Basic Presentation Structure

13.I do not interested in infographics taking too much time to read.

14.I do not trust infographics whose references are not indicated.

15.I do not read an infographic if the information presented is not up-to-date.

0.831

16.I do not understand the message given by infographics that have too much visuals.

0.743

\section{Retention/Memorability}

17.I think visualisations in infographics make more memorable what I learn from them.

18.I remember information that I learned from infographics easier compared to plain text materials.

19. As infographics present critical information required to be learnt on a subject, I learn the conveyed information in a better way compared to other learning materials.

\section{Role in Learning Process}

20.I prefer to read an infographic rather than reading a plain text to learn same subject.

21.Before checking other sources concerning a subject I am trying to learn, I prefer reading infographics, if there are any.

22. To gain an idea about a subject I will be learning, I first investigate/examine the infographics on the subject.

23. While making a search to learn about a given subject, I am able to find a sufficient number of infographics prepared in my native language. 


\subsubsection{Internal Consistency}

Internal consistency tests were conducted to assess the questionnaire. Cronbach's alpha coefficient was used to determine the internal consistency of the questionnaire. Internal consistency tests were conducted in such a manner as to explain the entire questionnaire and each factor individually. In the internal consistency test of the questionnaire, Cronbach's alpha was calculated to be 0.837 . Cronbach's alpha values for each factor are given below.

- Factor 1: 0.863

- Factor 2: 0.749

- Factor 3: 0.750

- Factor 4: 0.754

- Factor 5: 0.679

- Factor 6: 0.678

\subsubsection{Respondent Opinions}

The opinions of the respondents who filled in the questionnaire on infographic readers were evaluated. The mean score of the answers given by the respondents to the questionnaire items are as shown in Table 3.

As shown in Table 3, respondents considered that infographics have a high level informativeness. Respondents strongly agreed with all statements concerning the informativeness of infographics. They stated that visuals facilitate learning, that infographics are more informative than texts, and that the presentation of information within a context in infographics facilitates learning.

Respondents have various preferences in relation to the use of infographics in learning processes. Respondents first look at the title of a infographic to read it $\left(\bar{\aleph}_{\text {mean }}=4.31\right)$. Another factor that affects the preference of infographics is the visuals. Respondents described that visuals are an important reason for preferring infographics. Furthermore, they stated that social media sharing components on the infographic, as well as the persons or organisations that prepared the infographic, are also important.

Respondents agreed with all statements regarding the factor named Sharing. They stated that they share infographics with acquaintances who might be interested. They also expressed that they share infographics prepared in compliance with copyrights. Among visual-based materials, infographics have the highest rate of sharing. Moreover, respondents stated that they share infographics on social media platforms.

As is seen in Table 3, respondents described that they do not prefer infographics that take a long time to read. It was observed that infographics that are not up-to-date, and whose reference sources are not indicated, were not preferred by the respondents. The respondents neither agreed nor disagreed with the statement that excessive visualisation adversely affects the informativeness of infographics.

Table 3 shows that the respondents strongly agreed with the statements associated with the factor named Retention/Memorability. Respondents stated that infographics make learned information more memorable. They also considered that the memorability of information learnt from infographics is higher than the memorability of information learnt from texts $\left(\lambda_{\text {ort }}=4.25\right)$. Furthermore, they stated that infographics ensure better learning, as they convey critical information necessary for learning. 
Table 3. Questionnaire Scores

1. Informativeness

1. Visual representations used in infographics facilitate learning.

S Std.

2. I think infographics are more informative compared to long texts.

3. In infographics, presentation of information within a context facilitates learning.

2. Selection Preferences

4. I look at the title of the subject when choosing an infographic to read.

5. I look at the visuals used in the content when choosing an infographic to read.

6. I look at the content when choosing an infographic to read.

7. I look at the person or organization that prepared it when choosing an infographic to read.

8. I prefer that it has social media sharing tools when choosing an infographic to read.

3. Sharing

9. Among the different sources of learning with visual representations, I especially recommend infographics to people around me.

10.I share the infographics, which I liked, to my friends who may be interested.

11.I share infographics that are prepared in compliance with copyrights.

12.I share the infographics that I like on social media platforms.

4.31

0.114

$4.31 \quad 0.158$

$4.22 \quad 0.178$

$4.16 \quad 0.201$

$4.06 \quad 0.179$

$4.13 \quad 0.189$

4. Basic Presentation Structure

13.I do not interested in infographics taking too much time to read.

14.I do not trust infographics whose references are not indicated.

15.I do not read an infographic if the information presented is not up-todate.

16.I do not understand the message given by infographics that have too much visuals.

5. Retention/Memorability

17.I think visualisations in infographics make more memorable what I learn from them.

18.I remember information that I learned from infographics easier compared to plain text materials.

19. As infographics present critical information required to be learnt on a subject, I learn the conveyed information in a better way compared to other learning materials.

6. Role in Learning Process

20.I prefer to read an infographic rather than reading a plain text to learn same subject.

21.Before checking other sources concerning a subject I am trying to learn, I prefer reading infographics, if there are any.

22.To gain an idea about a subject I will be learning, I first 3.69 investigate/examine the infographics on the subject.

23. While making a search to learn about a given subject, I am able to find a 2.94 sufficient number of infographics prepared in my native language.

$\begin{array}{ll}4.31 & 0.138 \\ 4.25 & 0.162 \\ 4.13 & 0.160\end{array}$

Respondents prefer reading infographics to reading texts. Learners draw on infographics to have an idea about a new subject to be learnt. Infographics are among the first sources researched before checking the educational sources on a subject. Respondents neither agreed nor disagreed with the statement that they can find a sufficient number of infographics in their native language.

\section{Discussion and Recommendations}

Through the principal component analysis, a questionnaire consisting of 23 items and 6 factors was obtained. The internal consistency value of the entire questionnaire indicated that the scale's reliability was satisfactory. These results suggest that the questionnaire is sufficient to assess the opinions of infographic readers. 
Based on the opinions of the respondents, it is possible to say that infographics are highly informative. This may be due to the perception that infographics prepared by using the strength of visuals and visual narratives are more effective than classical learning environments. Similarly, Vanichvasin (15) noted that infographics raise awareness and facilitate remembering. Furthermore, Flemming and Levie (4) described that visuals are more memorable, and well-prepared visuals have positive effects on the cognitive processes of learners.

Title and visuals are the two most significant preference criteria for selecting infographics to read. This may be due to the understanding that titles and visuals need to rapidly reflect the information presented in the infographic. Krum (5) indicates that readers focus on and pay attention to the titles so as not to waste time or examine an irrelevant infographic.

Infographics are shared with acquaintances who may be interested. This may be due to the view that the need for learning can satisfied expeditiously. Davis and Quiin (11) note that infographics allow for easy sharing and learning in cooperation, while also promoting communication. People prefer sharing infographics prepared in compliance with copyrights. This may be due to the understanding that information can be shared only if it is reliable. Flemming and Levie (4) describe that sources with higher reliability are more satisfying. Up-to-dateness and source references two other factors that affect the sharing of infographics. Infographics that do not possess such qualities may be considered unreliable by readers. Krum (5) states that infographics with no references cited are considered unconvincing by readers.

Readers think that information acquired through infographics are more memorable and retained more easily. This may be due to the fact that learners add new information to their existing schemas more easily, or create new schemas more easily. Similarly to the respondents' statements, Zinonyev (16) notes that visualisations facilitate the analysis of the message in the content and ensure remembrance.

Infographics are one of the materials preferred during learning processes. This may be due to the willingness of learners to learn subjects quickly and lastingly. Content presented in a ready-to-learn format in infographics, with the relationships within the content being clearly indicated, may have resulted in less cognitive burden and increased learners' satisfaction. As mentioned in the literature, cognitive burden makes it harder to learn and perceive the connections within the content (17).

In conclusion:

- Infographics ensure effective learning for readers.

- Infographics allow for permanent and memorable learning.

- Attention is paid to titles and visuals when adding infographics to the learning process.

- Infographics are shared with potential readers in need of learning.

- Compliance with copyrights is checked when sharing infographics.

- Infographics are among the materials preferred in learning processes.

This questionnaire was developed based on a study conducted with a group of respondents with a high level of computer literacy and good technology skills. Administering the questionnaire to groups with different profiles may further enhance its power.

\section{References}

1. Karaman, S., Yıldırım, S., \& Kaban, A. Öğrenme 2.0 yaygınlaşıyor: Web 2.0 uygulamalarının eğitimde kullanımına ilişkin araştırmalar ve sonuçları. inet-tr'08 - XIII. 
Türkiye'de İnternet Konferansı Bildirileri 22-23 Aralık 2008 Orta Doğu Teknik Üniversitesi, Ankara, (2008).

2. Atıcı, B., \& Yıldırım, S. Web 2.0 uygulamalarının e-öğrenmeye etkisi. Akademik Bilişim, 10, 10-12, (2010).

3. Yıldırım, S., Yıldırım, G., Çelik, E. \& Aydın, M. Bilgi grafiği (infografik) oluşturma sürecine yönelik öğrenci görüşleri, Journal of Research in Education and Teaching, 3(4), (2014).

4. Flemming, M. L., \& Levie, W. H. (Eds.). Instructional message design: Principles from the behavioral and cognitive sciences. Hillsdale, NJ: Educational Technology Publications, (1993).

5. Krum, R. Cool Infographics: Effective Communication with Data Visualization and Design. John Wiley \& Sons. NJ. USA, (2013).

6. Williams, F. M. Diversity, thinking styles, and infographics. In Proc., 12th International Conference of Women Engineers and Scientists, (2002).

7. Schroeder, R. Interactive Info Graphics in Europe--added value to online mass media: a preliminary survey. Journalism Studies, 5(4), 563-570, (2004).

8. Dick, M. Interactive Infographics and News Values. Digital Journalism,2(4), 490-506 (2014).

9. Lankow, J., Ritchie, J., \& Crooks, R. Infographics: The power of visual storytelling. John Wiley \& Sons., (2012).

10. Meeusah, N., \& Tangkijviwat, U. Effect of data set and hue on a content understanding of infographic. http://www.repository.rmutt.ac.th/xmlui/handle/123456789/1263 (Retrieved Date:: 20.01.2015), (2013).

11. Davis, M., \& Quinn, D. Visualizing text: The new literacy of infographics. Reading Today, 31(3), 16-18 (2013).

12. Smiciklas, M. The power of infographics: Using pictures to communicate and connect with your audiences. Que Publishing, (2012).

13. Cochran, W. G. Sampling Techniques (Third ed.). John Wiley \& Sons, Inc, USA, (1977).

14. Kish, L. Survey Sampling, John Wiley \& Sons, Inc, NY. USA, (1995).

15. Vanichvasin, P. Enhancing the Quality of Learning Through the Use of Infographics as Visual Communication Tool and Learning Tool. Proceedings ICQA 2013 International Conference on QA Culture: Cooperation or Competition http://www.icqa2014.com/downloads/Proceeding_29.pdf\#page=135 (Retrieved Date: 19.01.2015), (2013).

16. Zinonyev, A. Data visualization in political and social sciences. http://arxiv.org/pdf/1008.1188v1.pdf (Retrieved Date:20.01.2015), (2010).

17. Sweller, J. Cognitive load theory, learning difficulty, and instructional design. Learning and instruction, 4(4), 295-312 (1994). 